\title{
Página Aberta \\ Caminhos da democracia nas políticas de descentralização da gestão escolar
}

\author{
Luciana Rosa Marques
}

\section{Resumo}

Este artigo discute as políiticas de democratização/descentralização da gestão escolar. Para tal, analisa estas políticas no município do Cabo de Santo Agostinho, região metropolitana do Recife, no período de 2003/2004. Partindo da idéia de que o ideário neoliberal apropriou-se da bandeira da democratização, originalmente defendida no campo progressista, escolheu-se um município cujas forças que estavam no poder, à época da coleta de dados, se colocavam no campo popular. Percebeu-se, neste estudo, que são veiculados conteúdos democráticos nas políticas educacionais municipais. Busca-se demonstrar, desta forma, que as políticas de descentralização podem contribuir para o estabelecimento de relações democráticas na escola e, portanto, para a sua transformação.

Palavras-chave: Política educacional. Gestão escolar. Democracia. Descentralização.

\section{Abstract}

Democratic roads in school administration policies (Decentralization)
This paper discusses the educational policies of decentralization and democratization of school management. It analyzes these policies in the municipality of Cabo de Santo Agostinho in the outskirts of Recife in 2003 and 2004. It is well known that the neo liberal system of ideas holds the banner of democratization and change sides depending upon its convenience. For this reason, it was chosen a municipal district whose political forces held the power at the time of data collection. It was noticed in this study that the democratic contents were. It was noticed in this study that the democratic contents were transmitted in the educational policies at the local level. It is quite evident that decentralization policies can contribute to the establishment of democratic relation ships in the school and, therefore, for its change.

Keywords: Education policy. School management. Democracy.

Decentralization. 
Resumen

\section{Caminos de la}

democracia em las políticas de

\section{descentralización de la gestión escolar}

Este artículo discute las políticas de democratización / descentralización de la gestión escolar. Para tal, se analizan estas políticas en el municipio de Cabo de Santo Agostinho, región metropolitana de Recife, en el periodo de 2003/2004. Partiendo de la idea de que el ideario neoliberal se apropió de la bandera de la democratización, originalmente defendida en el campo progresista, se eligió un municipio cuyas fuerzas que estaban en el poder, en época de recogida de datos, se colocaban en el campo popular. Se percibió, en este estudio, que se tratan contenidos democráticos en las políticas educativas municipales. Se busca demostrar, de esta forma, que las políticas de descentralización pueden contribuir para el establecimiento de relaciones democráticas en la escuela y, por tanto, para su transformación.

Palabras clave: Política educativa. Gestión escolar. Democracia.

Descentralización.

\section{Introdução}

A partir da década de setenta do século $X X$, o regime de acumulação fordista começa a viver crise fiscal e política, ao mesmo tempo em que são inauguradas transformações na base da economia capitalista em todo o mundo, particularmente o ocidental. Até então, tinha-se um modelo produtivo calcado na rígida hierarquia e especialização das tarefas, segundo o qual a produtividade do trabalho podia ser aumentada por meio da decomposição e fragmentação dos processos de trabalho, a partir de conjunto rigoroso de práticas de controle do trabalho, assim como de tecnologia e hábitos de consumo. São características, ainda, deste modelo produtivo a produção e consumo de massa e um modo de regulação que implica mecanismos que tratam de ajustar o comportamento contraditório e conflitante dos indivíduos.

A partir de 1973, quando se torna mais evidente a incapacidade de esse modelo conter as contradições inerentes ao capitalismo, começam a emergir nos países centrais novas formas de organização da produção, fundadas na flexibilização. $\bigcirc$ modelo pósfordista baseia-se no princípio da flexibilidade, como resultado da competição intensificada para reduzir os mercados; um processo de trabalho centrado num trabalho contingente, negociado e essencializado, baseado no trabalho em equipe, na autogestão e em múltiplas, mas básicas, habilidades, além de modos de regulação governados pela ideologia do livre mercado, individualismo e caridade privada.

As transformações ocorridas na base produtiva trazem consigo a "necessidade" de reformulação do aparato estatal. No modelo fordista, era preciso um Estado forte e controlador da economia, que fizesse investimentos em infra-estrutura, indispensáveis ao crescimento da produção e do consumo, através do qual se pretendeu regular o mercado, para manter o pleno emprego e uma economia orientada para a demanda. A administração estatal devia, ainda, sustentar a provisão pública das 
políticas sociais, oferecendo um "nível mínimo de vida", como elemento constitutivo da responsabilidade coletiva de todos os cidadãos e cidadãs.

No modelo neoliberal, por sua vez, o Estado deve ser mínimo, deixando-se à mão invisível do mercado a regulação econômica, "menos Estado e mais mercado" é a máxima neoliberal. Porém, a intervenção estatal torna-se necessária para compensar as falhas do mercado, tais como danos ao meio ambiente e combate ao monopólio, entre outras.

Neste cenário, a idéia de descentralização, que sempre foi identificada com aspirações por maior participação nas decisões e, portanto, com práticas democráticas substantivas, foi ressignificada (AZEVEDO, 2001). Isto decorre do êxito cultural e ideológico do neoliberalismo, que se expressa no argumento da inexistência de alternativas de desenvolvimento, enraizando a crença da inevitabilidade de novos modos de (des)regulação social. Com efeito, até o sentido das palavras foram ressignificados, como demonstra Boron (1999), exemplificando o caso do vocábulo reforma, que, de uma conotação positiva e progressista, que remetia a transformações sociais e econômicas orientadas para uma sociedade mais justa e igualitária, passa a ser reconvertido pelos ideólogos neoliberais, aludindo a processos e transformações de cunho involutivo e antidemocrático'.
Segundo Azevedo (2001), o que se procurou estabelecer em nosso país foi um replanejamento institucional, inspirado tanto no neoliberalismo quanto nas práticas de gestão industrial, a partir dos pressupostos da qualidade total. Procura-se, assim, privilegiar a administração por projetos, com objetivos estabelecidos previamente, de base local (expresso no processo de descentralização) e altamente competitivos. No entanto, nos próprios espaços locais, são observados germes de resistência a esse modelo gerencial, imposto pela reforma do Estado brasileiro. Assim,

[...] de uma perspectiva analítica mais global, é preciso termos presente que nenhuma orientação que vem de fora é transplantada mecanicamente para qualquer sociedade. Ao contrário, as diretrizes que, de um lado, estão desnacionalizando o Estado-nação em função da acumulação de capital são sujeitas a processos de recontextualização impingidos pelas características históricas da sociedade a que se destinam (AZEVEDO, 2001, p. 12).

A autora demonstra, ainda, que, no campo das políticas sociais, é possível a identificação de modos de atuação que procuram ressignificar as medidas impostas, direcionandoas à construção de um novo espaço público, capaz de forjar a cidadania emancipatória. São experiências que ainda se colocam em uma pequena dimensão quantitativa, mas que, por isso mesmo, devem integrar a ação investigati-

\footnotetext{
' Da mesma forma Lima (2002, p. 20) aborda a reconceituação de termos pelo ideário neoliberal que aparecem despojados de sentido político. Assim, "autonomia (mitigada) é um instrumento fundamental de construção de um espírito e de uma cultura da organização-empresa; a descentralização é congruente com a 'ordem espontânea' do mercado; respeitadora da liberdade individual e garante a eficiência econômica; a participação é essencialmente uma técnica de gestão, um fator de coesão e consenso". Assim, nesta perspectiva, "conceitos como 'autonomia', 'comunidade educativa', 'projecto educativo', continuarão a ser convocados, e até com maior freqüência, mas como instrumentos essenciais de uma política de modernização e racionalização, como metáforas capazes de dissimularem os conflitos, de acentuarem a igualdade, o consenso e a harmonia, como resultados ou artefactos, e não como processos e construções colectivas" (ld., Ibid., 2002, p. 31).
} 
va daqueles que acreditam que o conhecimento científico deve também portar um nível analítico que contribua para a transformação da perversa (des) ordem que hoje vivemos? ${ }^{2}$.

Essas mudanças encontram reflexos na forma proposta de gestão da educação. Com a adoção dos pressupostos neoliberais pelo poder central, a partir de 1995 começam a ser implantadas diretrizes no sentido de democratizar o sistema escolar e a gestão das escolas. Assistimos, assim, a uma série de ações que visam à democratização da gestão das escolas públicas brasileiras.

Cumpre considerar, contudo, que a discussão sobre a democratização da gestão escolar é uma demanda antiga de pesquisadores e trabalhadores da área, defendida por estes como um dos mecanismos importantes para se alcançar uma educação pública de qualidade, universal, como exercício de cidadania. Dessa forma, mesmo sendo implantada com base nos princípios neoliberais, a gestão democrática no sistema educacional público abre possibilidades para que se construa uma escola pública de qualidade, que atenda aos interesses da maioria da população brasileira, além de representar uma possibilidade de vivência e aprendizado da democracia, podendo, portanto, tomar um sentido diferenciado do proposto pelos fazedores de política. Nessa perspectiva, e admitindo o movimento dialético da história, podemos considerar que a implantação das novas diretrizes da política educacional nas escolas não está, em princípio, predeterminada, podendo, portanto, tomar sentidos diferenciados.

\section{Os sentidos da democracia na educação brasileira}

discurso da democracia vem permeando os debates e estudos na área da educação no Brasil, embora com significados diferenciados em cada momento histórico. A partir da década de 30, a democratização da educação referia-se, principalmente, à garantia de acesso à escola pública às crianças de 7 a 14 anos, observando-se recorrência aos temas do acesso à escola, da seletividade, da repetência e da evasão.

Na década de 80, com o restabelecimento do sistema democrático no país e a realização de eleições para prefeitos e governadores, observa-se mudança em relação ao sentido da democracia no debate sobre a educação ${ }^{3}$, embora a discussão da universalização da educação básica continuasse presente.

Consolidam-se o debate e demandas pela democratização do sistema educacional e das Unidades Escolares, que têm como pontos centrais, respectivamente, a descentralização/municipalização, a eleição direta para dirigentes escolares e a criação dos Conselhos Escolares. Observa-se, neste período, a implementação de mecanismos que assegurassem a participação da sociedade civil na formulação da política educacional em Estados como o Rio Grande do Sul, Paraná, Minas Gerais, Mato Grosso do Sul, Distrito Federal e Pernambuco, neste último Estado exemplificado pelos

\footnotetext{
${ }^{2}$ O que poderia ser percebido como o que Boaventura de Sousa Santos (2003) denomina de sociologia das emergências, dar visibilidade, revelar a diversidade e multiplicidade de práticas sociais, contrapondo-as às práticas hegemônicas.

${ }^{3}$ Segundo Weber (1993, p. 16) "a centralização extrema, com a conseqüente expansão de estruturas técnico-burocráticas, no interior das quais eram definidas as políticas públicas, ao longo do período autoritário, foi cedendo lugar, desde o final dos anos 70, em decorrência do grau de organização obtido pela sociedade civil, a processos participativos de planejamento e de gestão de políticas educacionais e da própria escola".
} 
Fóruns Itinerantes de Educação. Realizase, também, a mobilização sindical e acadêmica em movimentos pela democratização da escola pública, além da organização coletiva de Secretários Municipais e Estaduais de Educação com a criação da UNDIME e do CONSED em 1986.

Oliveira e Teixeira (1999) demonstram, a partir de revisão bibliográfica, que em determinados períodos históricos (1950, 1980 e 1990 $)^{4}$, o tema da municipalização do ensino, tendo como matriz a descentralização, foi mais discutido, identificando no processo de construção da educação municipal no Brasil a tendência à associação entre ações locais descentralizadas à democracia e políticas públicas de cunho mais centralizador ao ideário autoritário.

Souza e Farias (2004, p. 929) consideram que

o processo de elaboração da CF, de 1988, será então inspirado por aquela idéia de associação entre a descentralização e a democratização, daí emergindo um modelo de Federação descentralizado, com aspectos singulares, como o referente à explicitação do Município como ente federado no próprio texto Constitucional.

Nos anos 1990, o foco do debate sobre a democratização da educação é direcionado para as relações internas da escola, que deveriam ser democráticas, com a participação da comunidade escolar em sua gestão, sendo regulamentada, inclusive, pela $\mathrm{LDB}^{5}$. Dessa forma, a democratização das relações na escola torna-se uma exigência legal, que a comunidade escolar deve assumir.

A gestão democrática das Unidades Escolares públicas brasileiras ganha terreno institucional quando passa a ser defendida pelo Estado neoliberal ${ }^{6}$, como forma de garantir a eficiência e eficácia do sistema público de ensino. Por isso, não tem significado, muitas vezes, avanços na construção de uma escola pública de qualidade, que atenda aos interesses da maioria da população brasileira.

Percebem-se, neste modelo, a correlação entre as novas formas de organização produtiva e a implantação de políticas educacionais direcionadas à descentralização/ desconcentração da gestão das Unidades Escolares. A administração descentralizada faz-se necessária em função da inoperância da máquina burocrática, conferindo autonomia às escolas, inibindo, assim, riscos de perturbações indesejadas ao sistema, já que a participação do coletivo na gestão da escola aumenta à medida que aumentam suas responsabilidades (BRUNO, 1997).

Constata-se a intervenção de organismos internacionais, como Banco Mundial, UNESCO, CEPAL, entre outros, nas políti-

\footnotetext{
${ }^{4}$ Segundo elas (OLIVEIRA; TEIXEIRA, 1999), de 1991 a 1993 os trabalhos abordavam mais as políticas de municipalização do ensino e sua implantação, e de 1995 a 1997 os trabalhos focalizavam a gestão do ensino municipal.

${ }^{5}$ Conforme evidenciam os artigos 14 e 15.

${ }^{6}$ De acordo com Martins (2002, p. 121) "[...] a pauta defendida por setores progressistas e de esquerda a partir dos anos 1980 - necessidade de redistribuição do poder, maior atenção aos segmentos excluídos das políticas sociais, descentralização e autonomia de decisões às instâncias locais - emergiu com a legitimidade política necessária para ser efetivada nos anos 1990, paradoxalmente vinculada, porém, a uma nova dinâmica de gestão do Estado. A partir daí foram propostas novas formas de articulação com o setor privado lucrativo ou não lucrativo para que o Estado pudesse focar suas ações estabelecendo prioridades".
} 
cas educacionais latino-americanas, a partir da implantação de reformas que seguem o receituário destes organismos, os quais apesar de distintos em termos de suas prioridades e focos, evidencia-se a defesa: da descentralização como forma de desburocratização do Estado e de abertura a novas formas de gestão da esfera pública; da autonomia gerencial para as unidades escolares e, ainda, da busca de incrementos nos índices de produtividade dos sistemas públicos, marcadamente sob inspiração economicista e neoliberal (SOUZA ; FARIA, 2004, p. 927-928).

No entanto, apesar de implantada com base no modelo neoliberal, a institucionalização da gestão democrática pode representar avanços na forma de condução do dia-a-dia da escola, tendo em vista que as políticas educacionais ganham materialidade no locus de sua implementação.

Desde 1980, as forças progressistas reivindicam que a gestão das Unidades Escolares se dê de forma democrática, combatendo o centralismo que tem caracterizado a política educacional brasileira. Com a participação na definição dos rumos da escola, os que compõem a comunidade escolar têm a possibilidade de vivenciar um processo diferenciado de gestão da coisa pública, que passa a ser também de sua responsabilidade, contribuindo, assim, na construção de sua cidadania.

Como bem coloca Abranches (2003, p. 18), a descentralização só existe no momento em que as decisões locais possuem uma certa autonomia e emanam de uma coletividade e não do Estado. O ponto central a ser considerado no processo de descentralização é que este pode estimular e abrir oportunidades para a participação social, mediante o deslocamento dos centros decisórios - a descentralização é um meio para favorecer a participação. Por outro lado, a descentralização só se torna possível pela participação.

Neste cenário, nas décadas de 80 e 90, parece ganhar força, tanto em nível acadêmico como no das políticas educacionais, a discussão da democracia participativa como forma de garantia da democratização das relações que se estabelecem na escola, particularmente em sua gestão. No entanto, percebe-se que o tema não se apresenta de forma consensual. Se para os defensores da agenda neoliberal a defesa da participação se coloca com o fito da desresponsabilização do Estado para com as políticas sociais, para os setores progressistas a democracia participativa é entendida como forma de alargamento dos direitos sociais.

Compreende-se, portanto, que as políticas que visam implementar a democracia em escolas da rede pública não podem ser consideradas como um movimento de mão única. Se por um lado, os preceitos do neoliberalismo nos indicam a intenção privatista destas políticas, por outro, elas podem ser colocadas no campo progressista, buscando a construção de um espaço público democrático ${ }^{7}$, tendo em vista que a democratização do Estado brasileiro sempre esteve na pauta das lutas da sociedade civil.

Neste contexto, a educação, na quali-

\footnotetext{
${ }^{7}$ Tal entendimento direcionou a escolha de um município cuja gestão se colocava no campo progressista à época da coleta de dados, para a realização de nosso estudo empírico.
} 
dade de uma pratica social, pode prestar sua parcela de contribuição ao processo de democratização da sociedade brasileira e à construção de um projeto social comprometido com os anseios da maioria. Em que pese a escola não construir sozinha uma alavanca de transformação da sociedade, o seu concurso é essencial para a construção e consolidação de uma sociedade justa. São evidentes os seus limites, mas não se forja uma sociedade democrática sem a sua efetiva participação. Ela é, sem dúvida, um dos mecanismos viabilizadores de um modelo societal equânime. (COSTA; SILVA, 1998, p. 104).

Segundo Bastos (2002), a gestão democrática da educação abre a perspectiva do resgate do caráter público da administração pública, estabelecendo o controle da sociedade civil sobre a escola pública e a educação, garantindo a liberdade de expressão, pensamento, criação e organização coletiva e, ainda, facilitando a luta por condições materiais para a aquisição e manutenção dos equipamentos escolares, bem como de salários dignos para os profissionais da educação.

Desta forma, a gestão democrática de escolas públicas pode ser incluída no rol de práticas sociais que podem contribuir para a consciência democrática e a participação popular e, portanto, para a democratização da própria sociedade. $\bigcirc$ estudo da democracia na gestão de escolas públicas pode, portanto, contribuir para o entendimento da democratização da sociedade, na medida em que busca esclarecer como mudanças geradas pelas políticas de democratização sobre ela repercu- tem.

\section{As políticas de descentralização/ democratização da gestão escolar no Cabo de Santo Agostinho}

A fim de compreender o processo de implementação das políticas de democratização da gestão escolar e o sentido da democracia atribuído às mesmas, recorremos à fala das Secretárias Municipais de Educação e de Desenvolvimento Social e Promoção Humana. Tal resgate histórico nos parece importante, na medida em que consideramos que a construção democrática é um processo que se cristaliza lentamente e que não é implantado "do dia para a noite" ou "de cima para baixo".

As políticas de democratização solidificadas no município tiveram seu germe de implantação em 1982, com o processo de redemocratização do país. Naquele momento, as forças de oposição, pela primeira vez, chegam ao poder no município, tendo à frente o grupo do prefeito que estava à frente da prefeitura na época da coleta de dados.

No Estado de Pernambuco houve a eleição de vários prefeitos do campo progressista, em que pese o governo do Estado, nesta época, ainda estar em mãos das forças conservadoras. Tal quadro incentivou a organização coletiva dos municípios, no sentido de aglutinar forças para a consolidação de suas políticas, particularmente dos Secretários de Educação.

Assim, as Secretarias Municipais de Educação da Região Metropolitana do Recife começaram a trabalhar de forma cole- 
tiva, buscando maior força no enfrentamento ao governo estadual. Desse movimento, que tinha como bandeira a universalização do ensino, começa a surgir a necessidade de ampliação desta articulação que, posteriormente, viria a se consolidar nacionalmente através da UNDIME.

Com a eleição de Miguel Arraes em 1986 e a retomada do governo estadual de Pernambuco pelas forças de esquerda, cinco municípios da Região Metropolitana (Cabo de Santo Agostinho, Paulista, Olinda, Camaragibe, Itapissuma) e Moreno (que não integra a Região Metropolitana) consolidam um consórcio para administrar coletivamente recursos de um programa financiado pela FIDEM, denominado Nova Escola. Neste projeto, trabalhou-se uma nova metodologia com os alunos, considerados como sujeitos de sua aprendizagem, em um momento em que o construtivismo ainda não se colocava como a metodologia mais apropriada ao processo de ensino aprendizagem, além do trabalho com educação de jovens e adultos. $\bigcirc$ mérito de iniciativas deste tipo estava na redefinição política da utilização de recursos federais no nível municipal.

Assim, foi possível a apropriação de uma política hegemônica e a sua transformação em uma não hegemônica, através de uma prática articulatória, na construção do significado de uma política educacional. Os Secretários precisavam dos recursos que vinham do Governo Federal e não podiam abrir mão deles em função de divergirem politicamente das orientações para sua utilização. No entanto, conseguiram redirecionar a sua utilização e implantar ações que apontavam para a democratização do acesso à educação e para o estabelecimento de relações democráticas no sistema escolar.
Percebe-se, ainda, que, no discurso da Secretária de Desenvolvimento Social, é muito presente a concepção da municipalização como fortalecimento do poder local e democratização das políticas sociais.

Neste período, começa a ser discutida a questão da eleição direta para dirigentes escolares no município do Cabo, cidade que implantou o processo de eleição direta em 1990, época em que começaram a ser organizados os Conselhos Escolares.

A eleição dos diretores foi encarada como mecanismo de rompimento com as indicações políticas dos dirigentes escolares que vinham marcando a política educacional brasileira. Tal prática, implantada como medida de impacto, visava à construção de uma forma diferenciada de nomeação dos dirigentes educacionais, historicamente relacionada à barganha política.

No entanto, a avaliação feita atualmente deste processo, pelas secretárias de educação e de desenvolvimento social, demonstra que ele foi, de certa forma, precipitado, havendo a necessidade de muitas reformulações e certos "cuidados" na retomada de eleições diretas. Os gestores perceberam que a eleição direta, embora importante, por si só, não era capaz de garantir a implantação de práticas democráticas na gestão das escolas, compreensão que, inclusive, retardou a reimplantação desta política na gestão analisada, devido ao entendimento de que era preciso, primeiramente, fortalecer práticas democráticas na gestão das escolas e, somente, posteriormente, retomar a eleição direta para dirigentes escolares. 
Em 1986, foi eleito um novo prefeito que, embora pertencesse ao mesmo grupo político, não deu continuidade às políticas que vinham sendo implantadas. Este, por sua vez, foi sucedido por outro, do campo da direita, que, segundo os depoimentos, "sucateou" o município. Esta retrospectiva nos ajuda a entender as características da gestão, tanto no nível de um modelo administrativo alternativo, quanto no nível das prioridades e dos princípios e diretrizes políticas que ela adotou.

Em 1996 o atual grupo político volta ao poder, tendo à frente o mesmo prefeito, que se reelegeu em 2000, perdendo as eleições de $2004^{8}$. O governo reiniciou a gestão nas bases anteriores e, na segunda gestão (2000/2004), resolveu mudar o formato administrativo, ampliando o processo de participação e criando mecanismos institucionais. Nasceram, assim, as chamadas áreas temáticas, que formulam as políticas para uma determinada área. Por exemplo, a Secretaria de Desenvolvimento Social e Promoção Humana congrega seis secretarias executivas (educação, saúde, programas sociais, esporte e lazer, cultura e turismo). A cidade foi dividida em quatro (4) regiões administrativas cada uma com um secretário que também compõe o primeiro escalão do governo, que, "fundamentalmente articula as ações políticas e as ações dos planos setoriais dentro de sua área e acompanha as ações do executivo junto com os Conselhos Consultivos", além de monitorar as ações da secretaria temática, junto com a população.

Cada área temática tem a ela vinculadas as Secretarias Executivas e as Secretarias Regionais, onde a política é monitora- da. A população apresenta suas demandas à prefeitura através dos Conselhos Consultivos, que interagem com as Secretarias Regionais e estas com as Executivas.

Dessa forma, busca-se a integração de todas as políticas de uma mesma área. Há um programa de desenvolvimento institucional que consiste na elaboração de um plano de ações setoriais anuais que é discutido em várias instâncias, havendo reuniões mensais com o colegiado de secretários executivos, bimestrais com secretários executivos e gerentes e trimestrais com secretários executivos, gerentes e coordenadores. $\bigcirc$ objetivo destas reuniões é fazer com que cada coordenador se junte com os outros coordenadores e vá integrando as ações por baixo, na ponta.

Assim, a prefeitura busca a otimização das ações e o estabelecimento de relações mais horizontais na definição e implementação de políticas públicas. No nível da execução, as ações são implantadas a partir de um plano de atividades demandadas pelo orçamento participativo, em que os conselheiros definem a utilização dos recursos municipais.

Para o controle das políticas "macro" existem os conselhos setoriais (Saúde, Educação, Criança e Adolescente, Cultura, Assistência Social, Uso Abusivo de Drogas), que buscam uma maior integração com os Conselhos Consultivos.

Em relação aos recursos há uma planilha, definida anualmente, de domínio público, em que são ordenadas todas as despesas e os recursos correspondentes ao pagamento das mesmas. Dessa forma, não

${ }^{8}$ Nossa pesquisa de campo foi realizada em 2003/2004, antes do processo eleitoral. 
há o ordenamento de despesas pelo Prefeito, mas sim, pelos Secretários Executivos que podem, inclusive, remanejar recursos excedentes, após discussão com os ConseIheiros, que são da regional e que atuam em todas as secretarias, eleitos pela comunidade para mandato de dois anos.

O discurso das gestoras e os documentos analisados mostram que a democratização das relações nos espaços públicos municipais se basearam em uma compreensão cidadã da gestão da coisa pública. Desta forma, democratizar, no caso, não passou simplesmente pela busca da eficiência, como preconizado pelo neoliberalismo, mas pela formação de uma cultura política que se baseia na construção de relações democráticas na esfera pública. Assim, o Estado aparece com a preocupação da construção de sujeitos sociais, sendo possível admitir com Santos (2001, p. 77) que é nas

[...] novas formas de experimentação institucional que podem estar os potenciais emancipatórios ainda presentes nas sociedades contemporâneas. Esses potenciais, para serem realizados, precisam estar em relação com uma sociedade que aceite renegociar as regras de sua sociabilidade acreditando que a grandeza social reside na capacidade de intervir e não de imitar.

O discurso da Secretária de Promoção Humana destaca a importância da participação na construção de um espaço público diferenciado, onde a coisa pública é entendida como "nossa", e não, como um local "sem dono". Para tal nos fala de duas esco- las, uma ao lado da outra, em que, embora estando no mesmo bairro, com as "mesmas" características, "mesmas" pessoas, "mesmas" relações sociais, uma é constantemente pichada, roubada e depredada, enquanto que, em relação à outra, além de apresentar uma ótima conservação, a comunidade escolar se mobiliza em qualquer tipo de situação?. A diferença, segundo ela, está exatamente no movimento democrático que a escola faz.

\section{Os projetos e programas de democratização da gestão escolar}

A secretaria executiva de educação se organiza em torno de gerências. Uma delas é a gerência de gestão democrática que é responsável pela implantação/ condução dos projetos e programas de democratização da gestão escolar: a formação continuada dos gestores escolares, a formação continuada dos Conselheiros Escolares, o Programa Educação com Você e o programa de formação dos grêmios estudantis, que serão tratados a partir da análise dos documentos de proposição/divulgação dos mesmos e da entrevista com a Secretária Executiva de Educação.

\section{Formação continuada dos gestores escolares}

O programa de formação continuada dos gestores escolares atende oitenta e nove (89) escolas, cento e trinta e nove (139) gestores e seis (06) formadores, tendo como objetivo o aprofundamento dos fundamentos teóricos e práticos dos princípios da gestão democrática e mecanismos de participação, salientan-

\footnotetext{
9 Ela exemplifica, contando que, em um fim de semana de muita chuva, o muro da escola caiu e a lama entrou em suas dependências. Quando, na segunda-feira, funcionários da Prefeitura foram realizar a limpeza e reconstrução do muro, encontraram no local vários pais, que já estavam lavando a escola.
} 
do que este é "um processo de aprendizagem dos diferentes atores sociais, que reforça a cidadania", além do destaque da interlocução com a sociedade civil, como condição de melhoria da qualidade do ensino.

Foram previstas quatro (4) oficinas temáticas para o ano de 2003: uma (1) sobre construção do regimento escolar, uma (1) sobre reconstrução do projeto políticopedagógico, uma (1) sobre o Plano Municipal de Educação, e outra sobre gerência e gestão da escola e, também, três (3) seminários, versando sobre gestão democrática da educação, avaliação e autonomia da escola pública.

Por fim, o documento enumera as contribuições da formação continuada ${ }^{10}$ :

- Aprendizagem permanente;

- criação e recriação de estratégias de trabalho;

- socialização de experiências;

- compartilhamento e reflexão sobre a prática com os colegas;

- modificação dos procedimentos; e

- desenvolvimento pessoal.

A nosso ver, uma gestão efetivamente comprometida com a democratização das relações no interior da escola deveria estar atenta à formação de seus dirigentes nesta perspectiva. Sabemos do caráter hierárquico característico da educação brasileira, além das fragilidades na formação dos profissionais da educação. Não será, pois, "da noite para o dia" que a escola se tornará democrática, nem tampouco a democracia será implantada por decreto.

Os dirigentes têm um papel fundamental neste processo, em função da sua posição de liderança nas Unidades Escolares. Além disto, como bem coloca o documento, os processos de participação democrática constituem processos de aprendizagem coletiva. Nesse sentido, é interessante a preocupação da Secretaria de Educação em oportunizar a possibilidade da formação visando à construção de uma gestão democrática, e à criação de espaços de troca de experiências.

Em estudo anterior desenvolvido nas escolas do município, concluímos ser salutar observar que os diretores caracterizam a escola autônoma como aquela em que há a participação do coletivo, devido à sua posição de liderança na comunidade escolar, o que deve orientar práticas democráticas na gestão das Unidades Escolares. Além disso, esse seria o segmento que estaria "ameaçado" com a participação, pois historicamente as decisões têm sido de responsabilidade deles. A interpretação dos dirigentes sobre a autonomia vincula-a à participação, trazendo à tona a divisão do poder que essa autonomia acarreta. Se o planejamento torna-se coletivo e a comunidade escolar participa das decisões, o poder passa a ser compartilhado, não mais centrado na figura do diretor, que se torna um líder que vai estar à frente da execução do que foi decidido coletivamente (MARQUES, 2000, p. 96).

Tal achado, a nosso ver, reforça a importância de ações que visem à formação continuada dos dirigentes escolares, tendo como objetivo a consolidação de relações democráticas nas Unidades Escolares.

\footnotetext{
${ }^{10}$ É interessante que estas contribuições são apresentadas de forma circular, não havendo uma hierarquização das mesmas.
} 
Tivemos, ainda, a oportunidade de, em um dos momentos de encontro para formação, apresentar e discutir o referido trabalho com os dirigentes. Observamos como foi rica a reflexão de um estudo científico realizado a partir das experiências vivenciadas por alguns dos participantes da reunião. Participamos de um intenso momento de troca de experiências e de aprendizagem coletiva, no qual dificuldades foram expostas e avanços compartilhados. Consideramos, assim, esta experiência como uma forma de democratização de nosso conhecimento, certificado pela academia, que é compartilhado com os sujeitos de nossa investigação, oportunizando um crescimento mútuo e recíproco.

\section{A formação continuada dos Conselheiros Escolares}

No material elaborado pela secretaria, - Conselho Escolar é definido como uma instância de discussão, negociação e decisão, onde a hierarquia dos cargos é substituída pela representatividade de interesses dos diferentes segmentos da escola. Tem natureza consultiva, deliberativa e fiscalizadora, constituindo-se no órgão máximo da escola, com as seguintes funções:

- Garantir a gestão democrática da escola;

- zelar pela qualidade da educação escolar oferecida à população;

- assegurar a articulação da escola com a comunidade;

- acompanhar e fiscalizar os trabalhos da escola;

- promover a divulgação das ações da escola na comunidade interna e externa;
- manter articulação com a Secretaria de Educação, visando a assegurar as condições necessárias ao funcionamento adequado da escola;

- implementar diretrizes e metas estabelecidas pela Secretaria de Educação;

- coordenar e discutir a elaboração do Projeto Político-pedagógico e acompanhar a sua execução, em conjunto com a equipe diretiva;

- aprovar projetos pedagógicos que desencadeiam ações educativas;

- propor, apoiar e defender medidas que visem à melhoria da organização e do funcionamento da escola;

- adequar os conteúdos estabelecidos à realidade sociocultural do aluno;

- coordenar e fiscalizar a organização e realização das eleições diretas para gestores das escolas;

- apreciar relatórios anuais da escola, analisando seu desempenho segundo as diretrizes e metas estabelecidas pela comunidade escolar; e,

- acompanhar o desempenho dos gestores, convocando, quando for o caso, a Assembléia Geral para destituição da função, conforme regulamenta a lei.

Percebe-se, analisando as funções do Conselho definidas neste material, que elas se colocam no campo administrativo e pedagógico. $\bigcirc$ Conselho tem a atribuição da definição e acompanhamento de questões pedagógicas, como a elaboração e acompanhamento do Projeto Políitico-pedagógico, e atribuições administrativas como o acompanhamento do trabalho do gestor e a proposição de medidas de melhoria da organização escolar. A atividade gerencial estaria a cargo da direção da escola, que deve respeitar as deliberações do Conselho Escolar. 
Os Conselhos Escolares são colocados, ainda, como mecanismos de democracia participativa, em complementaridade à representativa, na medida que há a participação nas decisões políticas, no controle e avaliação das ações.

\section{Segundo o documento}

a gestão democrática participativa firma a democracia representativa e aponta para avançar a democracia participativa [...] a prática da democracia participativa fortalece a cidadania e tecnicamente qualifica o ensino. Numa gestão compartilhada as pessoas aprendem a exigir qualidade de conteúdos e aprendem a gerir o processo, sendo co-responsável das ações definidas pela escola, concepções de política e avaliação dos resultados.

No sentido de garantir o cumprimento destas atribuições e funções dos Conselhos Escolares foi implantado o programa de formação dos Conselheiros Escolares, cujo objetivo é

contribuir para o processo de fortalecimento da gestão democrática, através da participação de seus diversos atores sociais que fazem o Conselho da Escola para garantir a articulação escola / comunidade, assegurando a todos o direito público, subjetivo, à educação básica de qualidade.

Para tanto, foi prevista, no ano de 2003, período da coleta de informações desta pesquisa, a realização de seminários sobre o tema "Gestão Democrática e Democracia Participativa", a realização de oficinas na área de recursos financeiros, a articulação de fóruns regionais, e a realização de seminário para socialização das oficinas.
Tivemos acesso aos materiais trabalhados até a data da coleta dos dados documentais (28/07/2003). As apostilas tratam das características, constituição, funções e atribuições do Conselho Escolar.

Dois pontos nos chamaram atenção. Primeiro, o material que aborda a aplicação dos recursos financeiros provenientes do Programa Dinheiro Direto na Escola, que esclarece as possibilidades de utilização destes recursos, as proibições para sua utilização, além dos procedimentos para uma correta utilização e formas de prestação de contas. Nesse material, é explicado por exemplo, a diferença entre recursos de custeio e de capital. Anotamos que a maior parte dos Conselheiros, incluindo-se aí os profissionais da educação e dirigentes, não tem conhecimento e habilidade no trato com recursos financeiros. Neste sentido, é bastante interessante que a Secretaria de Educação dê subsídios a estas pessoas para que entendam melhor os processos de financiamento da educação, principalmente porque têm responsabilidade direta na aplicação dos recursos, na medida em que esta é uma atribuição do Conselho, o qual, por sua vez, deve prestar contas à população e aos órgãos fiscalizadores acerca de sua utilização.

O segundo aspecto que nos chamou atenção foi um diálogo reproduzido em uma das apostilas:

- É a parte do ensino. O Conselho discute se os alunos têm [sic] apreendido, se tem tido muita repetência na escola.

- Mas a gente não estudou, não fez faculdade [...]

Como poderemos estudar junto com os professores dizendo como eles devem ensinar? 
- Do nosso jeito, a gente conhece coisas que podem ajudar o trabalho dos professores.

- Diz [sic] que outro dia, uns professores queriam que o meu vizinho falasse sobre como surgio [sic] o bairro e como ele foi crescendo. Sabe para que?

- Para depois as crianças estudarem isso na escola.

- Nossa! É mesmo

- A professora também disse que tem eleição para os representantes dos Conselhos Escolares.

- Eu vou me informar, porque esta eleição também é muito importante.

- Todos participam da eleição do Conselho Escolar. Pais, funcionários, alunos, professores, e elegem seus representantes.

É interessante observar que o diálogo indica possibilidades de participação dos pais a partir da valorização de seu saber. É comum se ouvirem críticas sobre a participação dos pais que vão à direção do seu "desconhecimento pedagógico", ao mesmo tempo em que eles, muitas vezes, se consideram "incapazes" de participar. Mesmo não dispondo de conhecimentos pedagógicos sistematizados, técnicos, existe a possibilidade de contribuição deles, na medida em que os pais e a comunidade dispõem de outros saberes que os técnicos não dominam.

Nesse sentido, tomando por base o pensamento de Santos, este trecho do documento nos traz uma possibilidade de "ecologia de saberes".

Com efeito, segundo Santos (2003, p. 747),

Toda ignorância é ignorante de um certo saber e todo o saber é a superação de uma ignorância particular. Deste princípio de incompletude de todos os saberes decorre a possibilidade de diálogo e de disputa epistemológica entre os diferentes saberes. O que cada saber contribui para este diálogo é o modo como orienta uma dada prática na superação de certa ignorância. $\bigcirc$ confronto e o diálogo entre os saberes é um confronto e um diálogo entre diferentes processos através dos quais práticas diferentemente ignorantes se transformam em práticas diferentemente sábias [...] esta ecologia de saberes permite não só superar a monocultura do saber científico, como a idéia de que os saberes não científicos são alternativos ao saber científico.

\section{Programa Educação com Você: um mecanismo de gestão}

O programa Educação com Você é apresentado como

[...] um dos mecanismos da gestão escolar que fortalece a sua autonomia através da interação / interlocução com os segmentos sociais do entorno da escola, tornado-os atores sociais coresponsáveis pelo controle das políticas educacionais.

Seu objetivo é o fortalecimento da gestão democrática pela participação da comunidade no controle do desenvolvimento educacional, tendo em vista a busca de uma escola competente e cidadã. Para tal, são previstas as seguintes ações: visitas às escolas, dia da educação com você e agrupamento das escolas por proximidade, que terão como participantes a Secretaria de Educação, Conselheiros Escolares, dirigentes, representantes das regionais, grêmios estu- 
dantis, agentes de saúde, pais e responsáveis e, ainda, representantes de ONGs. Tem, assim, a intenção de garantir o controle social das políticas públicas de educação municipal, a partir do envolvimento dos diferentes segmentos da escola e da sociedade civil. No sentido de tornar a população mais próxima do poder público, a Secretária de Educação vai às escolas para discutir as questões educativas com a população, podendo ser considerada, assim, um mecanismo de democracia participativa.

Segundo a Secretária Executiva de Educação, em 1998, a secretaria de educação, percebendo a necessidade de uma maior participação da população, criou o "Programa Educação e Você", no qual a equipe da secretaria vai à escola para estabelecer um diálogo com a comunidade escolar. De acordo com ela, "muita gente diz: não sei como vocês têm coragem de vir a uma escola que tem tanto problema. Mas tem que ir, a gente vai fazer o quê? Fazer de conta que os problemas não acontecem?

Os encontros do "Educação e Você" são organizados através da nucleação das escolas próximas e, geralmente, acontecem com duas ou três escolas. Neste momento é aberto um canal de comunicação entre a prefeitura e a comunidade escolar, no sentido de discutir e esclarecer as questões do cotidiano da escola. A Secretária se ressente da centralização da discussão em questões de merenda e falta de professores. Na verdade, sua expectativa era por uma maior discussão de questões pedagógicas. No entanto, relata-nos uma intervenção de uma mãe que questionava a metodologia de trabalho na educação infantil. Veja,

se a filha dela não sabe ler, por que ela trabalha com nomes? E foi interessante porque a gente pode ter oportunidade de refletir com a mãe, com os pais que estavam ali quanto à questão da concepção da alfabetização, por onde passa, que é importante que a criança entre em contato com o momento da leitura. Mas no seu universo, ela tinha razão, porque se a criança não sabe ler e você dana a ter papel para a menina ler, a ter atividade para fazer isto e aquilo, para ela era uma preocupação.

Este depoimento nos parece bem interessante, no sentido de ressaltar o caráter pedagógico da participação, utilizando-se aqui o pedagógico como construção de novos conhecimentos para ambas as partes. Podemos perceber um questionamento a um saber técnico por parte de uma mãe, leiga neste saber, que possibilitou a ela aprendizagem sobre o mesmo. Da mesma forma, proporcionou para a equipe da Secretaria o aprendizado de como a população percebe a alfabetização. Na perspectiva de Santos, esta troca também poderia ser caracterizada como uma ecologia de saberes, onde diferentes saberes se interpenetram e constróem-se mutuamente. Podemos, ainda, ilustrar esta argumentação com o seguinte fragmento da entrevista com a Secretária:

Eu acho que um olhar de um pai, de uma mãe, eles dão sugestões que às vezes dá um estalo, realmente, ele pode, tem como isso dar certo, eu acho que por aí ajuda.

Tal compreensão nos remete ao próprio documento elaborado para a mobilização da comunidade escolar com o Conselho Escolar, analisado anteriormente, que valoriza o saber da comunidade. Sabemos que pais e mães, em sua maioria, não dominam o saber técnico-pedagógico, no en- 
tanto, isto não significa a impossibilidade de contribuir com as atividades desenvolvidas no cotidiano escolar, na medida em que há um saber que deve ser considerado e trazido para dentro da escola.

A Secretária nos coloca, ainda, que, em geral, no início dos encontros as pessoas estão "armadas", colocando-se na posição de que "se o governo está lá é para bater", mas ao final dos encontros se começa a conseguir estabelecer a troca, e os participantes passam a sugerir e a opinar. Assim, este espaço participativo coloca a prefeitura mais perto da população. Segundo ela,

a fala do usuário dá para a gente uma dimensão muito próxima do real, por onde a gente pode estar direcionando nossas ações, porque você fica muito distante do que acontece na ponta efetivamente.

A idéia de confronto com os membros do governo indica que a população, em que pese as ações de participação levadas a cabo pelo Município, ainda não se sente como co-partícipe das ações do poder público. Mesmo havendo a preocupação da aproximação com a população, esta, em geral, parece entender o poder público como "inimigo" e não como um aliado, possibilitando uma soma positiva, que garanta autonomia ao Estado e aos atores sociais. Tal compreensão, supomos, não é compartilhada por aqueles que têm militância nos diferentes movimentos sociais.

\section{O programa de formação dos grêmios estudantis}

$\bigcirc$ programa de formação dos grêmios tem por objetivo "realimentar a gestão participativa nas escolas através dos grêmios estudantis, assegurando a liberdade e a co- responsabilidade de todos na construção de uma escola democrática, eficiente, de qualidade". São previstos seminários de socialização, fóruns de debates, visitas às escolas, articulação do lançamento do Programa Fome Zero, participação no congresso da UMES e publicação de materiais sobre grêmio estudantil. Além dos grêmios, os participantes envolvidos nestas ações seriam as ONGs, Secretaria de Educação, dirigentes escolares e UNE.

A implantação dos grêmios estudantis é uma das ações que visam à construção de espaços de participação na escola. É um programa que vem sendo desenvolvido pela gerência de gestão democrática e que encontra alguma resistência nas escolas, particularmente por parte de alguns dirigentes, que consideram o grêmio como um elemento "perturbador".

A Secretária de Educação, que entende ser esta uma instância importante de democratização do espaço escolar, vem buscando aproximar os grêmios estudantis da discussão das políticas públicas para a juventude, pois compreende que

o grêmio estudantil não pode deixar de estar antenado (sic) com as questões macro da sociedade, até porque o que forjou o movimento estudantil no País foi esse papel que ele teve de resistência, mas não pode ser só isso, porque senão, não assume o seu papel na escola. Tem que estar preocupado com a rotina da sua escola, como ela está respondendo suas competências, o seu papel. Eu gosto de puxar a discussão de grêmio para isso. Para que ele seja legítimo tem que partir da vontade dos meninos estarem fazendo. Agora eu acho que a gente tem um papel importante na me- 
dida em que pode estar abrindo espaço para o debate, puxando, sensibilizando.

Damos o mote, alguém vai pegar.

Parece-nos interessante a realização de ações voltadas ao fortalecimento do movimento de organização dos estudantes como mecanismo de democratização da gestão. Na maioria dos estudos que tratam do tema não são encontradas referências aos grêmios. Nestes trabalhos, a referência à participação dos estudantes, em sua maioria, se dá no âmbito da representação no ConseIho Escolar.

Tendo em vista o arrefecimento observado no movimento estudantil na atualidade, parece-nos interessante a preocupação da Secretaria de Educação com este segmento. Além disto, o fortalecimento dos grêmios contribui no aprendizado democrático, na medida em que fortalece e legitima a participação dos estudantes, propiciando o estabelecimento de espaços de conflito e de diálogo. Se tomarmos por base a compreensão de que na escola não aprendemos só conteúdos, mas também valores e práticas, os jovens que têm a oportunidade de vivenciar experiências democráticas em sua formação serão mais preparados ao exercício democrático na sociedade, pois o grêmio pode ser um espaço de aprendizagem da cidadania e da construção de novas relações de poder na escola.

\section{Buscando concluir...}

Neste artigo apresentamos o resultado de pesquisa realizada sobre as políticas educacionais de democratização/descentralização da gestão escolar no Município do Cabo de Santo Agostinho. Apesar de compreendermos que as políticas educaci- onais por si só não são capazes de garantir que as relações escolares se democratizem, sem a sua existência a democracia nas escolas e no sistema escolar não tem possibilidade de acontecer. Buscamos, portanto, descobrir o sentido atribuído à democracia nestas políticas.

Nossa pesquisa de campo, realizada através de análise documental e de entrevistas, nos mostrou que as políticas de descentralização da gestão escolar se colocam como "instrumentos" de construção da cidadania emancipatória, forjando, assim, um espaço público democrático. Não estão, portanto, coadunadas ao ideário neoliberal que busca tão-somente a eficiência e a eficácia da escola, com base nos pressupostos da qualidade total, sem preocupação com a qualidade social da escola, que está atrelada à construção da democracia emancipatória.

No Cabo de Santo Agostinho, o Estado, um dos espaços de regulação social, se mostra preocupado com a construção de sujeitos sociais autônomos. Assim, nas políticas educacionais são veiculados conteúdos democráticos, o que indica o seu avanço. Podemos considerar, desta forma, que, no município, existe uma regulação democraticamente partilhada que pode ser transformada em uma forma de emancipação. Há, portanto, uma soma positiva entre o poder local e a sociedade, baseada em uma relação virtuosa que se estabelece entre os atores sociais e o Estado.

No Município estudado, observamos que o discurso daqueles que estão no poder é edificado em um conteúdo democrático, que ele veicula e coloca como princípio da administração. 
Por fim, consideramos ser de fundamental importância a implementação de políticas de descentralização/democratização da gestão escolar tomando por base uma perspectiva cidadã da democracia. Se as políticas educacionais por si só não garantem a implementação de práticas democráticas nas escolas, elas são a con- dição de possibilidade de sua existência. Assim, só com base em políticas de descentralização que busquem a construção de uma gestão democrática, que contribua na formação cidadã da comunidade escolar a gestão escolar poderá efetivamente concorrer para a transformação da educação e da sociedade.

\section{Referências}

ABRANCHES, M. Colegiado escolar: espaço de participação da comunidade. São Paulo: Cortez, 2003.

AZEVEDO, J. M. L. Cidadania, desenvolvimento humano e reforma educacional. In: ENCONTRO DE PESQUISA EDUCACIONAL DO NORDESTE, 15., 2001, São Luís, 2001. Anais... São Luís, MA, [S.I.], 2001. 1 CD-ROM.

BASTOS, J. B. Gestão democrática da educação: as práticas administrativas compartilhadas. In: BASTOS, J. B. (Org.). Gestão democrática. Rio de Janeiro: DP\&A, 2002. p. 7-30.

BORON, A. Estado, capitalismo e democracia. Rio de Janeiro: Paz e Terra, 1999.

BRASIL. Lei n. 9.394, de 20 de dezembro de 1996. Estabelece as diretrizes e bases da educação nacional. Legislação, Brasília, DF, dez.1996. Disponível em: <http:// www.mec.gov.br/sef/fundef/Ftp/leg/em 1496.doc>. Acesso em: ago. 2006.

BRUNO, L. Poder e administração no capitalismo contemporâneo. In: OLIVEIRA, D. A. (Org.). Gestão democrática da educação: desafios contemporâneos. Petrópolis: Vozes, 1997.

CABO DE SANTO AGOSTINHO (PE). Prefeitura. Plano Municipal de Educação, 1997 / 2000. Cabo de Santo Agostinho, PE, 1997.

COSTA, C.; SILVA, I. Democratização da gestão escolar: uma tentativa de balanço. Revista de Educação da AEC, Brasília, DF, n. 109, p. 100-115, 1998.

LIMA, L. Modernização, racionalização e optimização: perspectivas neotayloristas na organização e administração da educação. In: LIMA, L.; AFONSO, A. J. Reformas da educação pública: democratização, modernização, neoliberalismo. Porto: Afrontamento, 2002. 
MARQUES, L. R. Projeto político pedagógico: construindo a autonomia da escola pública? As representações sociais dos conselheiros. 2000. Dissertação (Mestrado em Educação)-Universidade Federal de Pernambuco, Recife, 2000.

MARTINS, A. M. Autonomia da escola: a (ex) tensão do tema nas políticas públicas. São Paulo: Cortez, 2002.

OLIVEIRA, C.; TEIXEIRA, L. H. Municipalização e gestão municipal. In: WITTMANN, C.; GRACINDO, R. V. (Coord.). O estado da arte em política e gestão da educação no Brasil: 1991-1997. Brasília, DF: ANPAE, 1999.

SANTOS, B. S. Conhecimento prudente para uma vida descente: um discurso sobre as ciências revisitado. Porto: Afrontamento, 2003.

. Globalização: fatalidade ou utopia? Porto: Afrontamento, 2001.

SOUZA, D. B.; FARIA, L. C. Reforma do Estado, descentralização e municipalização do ensino no Brasil: a gestão política dos sistemas públicos de ensino pós-LDB 9.394/96. Ensaio: avaliação e políticas públicas em educação. Rio de Janeiro, v. 12, n. 45, p. 925-944, out./dez. 2004.

WEBER, S. Democratização e descentralização: política e práticas. Revista Brasileira de Administração Educacional, Brasília, DF, v. 9, n. 2, p. 9-25, jul./dez. 1993.

. Institucionalização do CONSED. In: CONSELHO NACIONAL DE SECRETÁRIOS DE EDUCAÇÃO (BRASIL). CONSED 10 anos: relatório de gestão: 19951996. Brasília, DF, 1996.

Políticas do ensino fundamental em revista: um debate pela democracia. In: $\overline{\operatorname{COSTA}}$, A. O. (Org.). Uma história para contar: a pesquisa na Fundação Carlos Chagas. São Paulo: Anablume, 2004.

Recebido: 01/09/2006

Aceito para publicação: 13/09/2006 